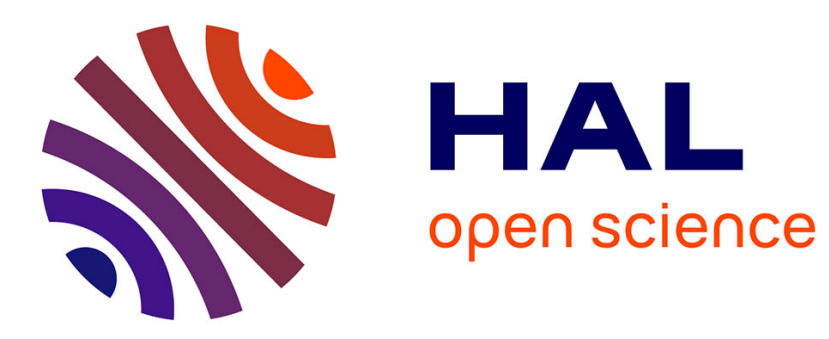

\title{
Unusual use of objects after unilateral brain damage. The technical reasoning model.
}

François Osiurak, Christophe Jarry, Philippe Allain, Ghislaine Aubin, Frédérique Etcharry-Bouyx, Isabelle Richard, Isabelle Bernard-Cadenat, Didier Le Gall

\section{To cite this version:}

François Osiurak, Christophe Jarry, Philippe Allain, Ghislaine Aubin, Frédérique Etcharry-Bouyx, et al. Unusual use of objects after unilateral brain damage. The technical reasoning model.. Cortex, 2009, 45, pp.769-783. halshs-00485306

\section{HAL Id: halshs-00485306 \\ https://shs.hal.science/halshs-00485306}

Submitted on 20 May 2010

HAL is a multi-disciplinary open access archive for the deposit and dissemination of scientific research documents, whether they are published or not. The documents may come from teaching and research institutions in France or abroad, or from public or private research centers.
L'archive ouverte pluridisciplinaire HAL, est destinée au dépôt et à la diffusion de documents scientifiques de niveau recherche, publiés ou non, émanant des établissements d'enseignement et de recherche français ou étrangers, des laboratoires publics ou privés. 


\title{
UnUSUal USE OF OBJECTS AFTER UNILATERAL BRAIN DAMAgE.
}

\section{The Technical Reasoning Model}

\author{
François Osiurak $^{1,2}$, Christophe Jarry ${ }^{1,2}$, Philippe Allain ${ }^{1,2}$, Ghislaine Aubin ${ }^{1,2,3}$, \\ Frédérique Etcharry-Bouyx ${ }^{1,2}$, Isabelle Richard ${ }^{3}$, Isabelle Bernard ${ }^{4}$, Didier Le Gall ${ }^{1,2}$ \\ ${ }^{1}$ Laboratory of Psychology UPRES EA 2646, Department of Psychology, University of Angers, France. \\ ${ }^{2}$ Neuropsychological Unit, Department of Neurology, University Hospital of Angers, France. \\ ${ }^{3}$ Neuropsychological Unit, Regional Centre for Functional Rehabilitation of Angers, France. \\ Department of Neurology, Hospital of Cholet, France.
}

Correspondence address:

Didier Le Gall

Unité de Neuropsychologie

Département de Neurologie

Centre Hospitalier Universitaire

4, rue Larrey

49033 Angers Cedex 01

France

Tel: 33 (0) 241354614

Fax: 33 (0) 241353594

E-Mail: DiLeGall@chu-angers.fr

Running head: The Technical Reasoning Model 


\section{AbSTRACT}

It has been suggested that gesture engrams, conceptual knowledge and/or the ability to infer function from structure can support object use. The present paper proposes an alternative view which is based upon the idea that object use requires solely the ability to reason about technical means provided by objects. Technical means are abstract principles which are not linked with any object representation (e.g., cutting involves the opposition between dense and permeable material). The technical reasoning model predicts that the inability to perform technical reasoning should impair performance in any situation requiring the use of objects (in a conventional way or not). Twenty left brain-damaged (LBD) patients, 11 right braindamaged (RBD) patients and 41 healthy controls were examined on experimental tests assessing the conventional use of objects (e.g., screwing a screw with a screwdriver), conceptual knowledge about object function, pantomime of object use and recognition of object utilization gestures. We also designed the Unusual Use of Objects test, which demands unusual applications of objects to achieve a purpose for which the usually applied object is not provided (e.g., screwing a screw with a knife). The key findings are that only LBD patients have more difficulties on the Unusual Use of Objects Test than controls or RBD patients, and that the severity of their impairment is correlated with that on conventional use of objects. Correlations with tests assessing conceptual knowledge as well as with tests of pantomime of object use and recognition of object utilization gestures were weaker. These results support the technical reasoning model and question the role of conceptual knowledge and gesture engrams in object use. Since the technical reasoning model also predicts two distinct technical disorders, the discussion focuses on the existence of these disorders in regard to individual performance profiles obtained in the Unusual Use of Objects test.

KEYwORDS: Action, Apraxia, Conceptual Knowledge, Gesture, Tool Use. 


\section{INTRODUCTION}

The fundamental psychological question of hominid tool use and manufacture has received little attention in neuropsychology (Goldenberg and Iriki, 2007; Johnson-Frey, 2004; Le Gall, 1992). This epistemological situation can be explained by the fact that, since the early twentieth century, a consensus has emerged that defective use of objects would pertain to the area of conceptual and/or of praxic disorders. The present paper discusses this perspective and proposes an alternative account in which impairment of object use is foremost viewed as the inability to reason about technical means provided by objects.

In a seminal work about apraxia, a disorder of skilled movement, Liepmann (1920) proposed that the difficulties which brain-damaged patients encounter when trying to use objects could be due to loss of movement memories or formula (hereafter called the "gesture engram hypothesis"). The inclusion of object use impairment in the area of motor rather than of conceptual disorders has been strongly questioned (Morlaas, 1928), and it is now wellestablished that damage to stored gesture representation would primarily result in impairment in the production of pantomimes and/or the recognition of object utilization gestures (Heilman et al., 1982). Interestingly, recent studies have shown that patients with difficulties in producing and recognizing pantomimes have diminished knowledge of skilled object manipulation when they are assessed with motor imagery (Buxbaum et al., 2005a) or multiple choice tasks (Buxbaum and Saffran, 2002; Buxbaum et al., 2003), suggesting that the deficit is not limited to movement execution stages of performance. These works highlight the importance of motor imagery in pantomime of object use. Nevertheless, the existence of gesture engrams remains an open question all the more so since no study has been able to provide a clear-cut explanation of why the performance of individuals with degraded knowledge about object manipulation generally improves when they are permitted to contact 
and use objects directly (for discussion, see Goldenberg, et al., 2004; Hermsdörfer et al., 2006).

It has been suggested that some brain-damaged patients are unable to use objects normally due to loss of conceptual knowledge about object function (Heilman et al., 1997; Ochipa et al., 1989, 1992). Consistent with this view (hereafter called the "conceptual knowledge hypothesis"), Hodges et al. (2000) reported high correlation in patients with semantic dementia between the degree of impairment of conceptual knowledge and the ability to demonstrate the use of common objects in isolation. Interestingly, their patients showed object use that was impaired to an extent consonant with their conceptual knowledge for the same items. However, there were a small number of instances in which the patients appeared to use an object more successfully than would be predicted by their knowledge about it. Furthermore, in line with previous reports of semantic dementia (Buxbaum et al., 1997; Lauro-Grotto et al., 1997), a number of the patients included in the study by Hodges et al. (2000) still engaged successfully in hobbies and sports requiring object use. Thus, Hodges et al. (1999, 2000; see also Bozeat et al., 2002) argued that several other factors, such as object affordances or mechanical problem-solving, might be influential. While emphasizing the key role of conceptual knowledge in the use of objects in isolation, these findings corroborate the assumption that intact conceptual knowledge is neither necessary nor sufficient to ensure good utilization in actions involving the use of several objects (Buxbaum et al., 1997; Hartmann et al., 2005).

In recent years, greater attention has been turned to the idea that object use might be based on a comparison of the structural properties of objects with the requirements posed by actions, that is, on a direct inference of function from structure (hereafter called the "direct inference hypothesis"). For assessing this ability, Goldenberg and Hagmann (1998) developed a test of mechanical problem solving requiring the selection and application of novel tools. These 
authors found a strong association in left brain-damaged (LBD) patients between mechanical problem-solving skills and the capacity to use familiar objects. Mechanical problem-solving skills can also be disrupted in patients with corticobasal degeneration, who are known to be impaired in everyday activities involving object use (Hodges et al., 1999; Spatt et al., 2002). Nevertheless, its has also been documented that brain damage can affect the use of familiar objects and mechanical problem-solving skills independently from each other, suggesting that object use would not be supported only by the ability to infer function from structure, but also by other cognitive processes such as conceptual knowledge (Bartolo et al., 2007; Goldenberg and Hagmann, 1998).

Another interpretation of these findings can be made, in which the use of multiple objects would depend solely on the ability to perform causal reasoning. The novel tool selection test developed by Goldenberg and Hagmann (1998) requires recognizing the technical means suitable for performing the task (e.g., cutting involves the opposition between dense and permeable material) from objects' physical properties. However, the identification of possible technical means might only be one of the components of causal reasoning about object use. Thus, it can be suggested that normal performance on the test of novel tool selection could not assure that causal reasoning is wholly preserved and, as a consequence, could be reported in patients who commit errors when using familiar objects.

The theoretical framework developed by Gagnepain (1990) and Le Gall (1998) proposes that the use of objects is guided by reasoning founded upon two abstract technical principles (hereafter called "technical reasoning hypothesis"). This perspective is based upon the assumption that there is no overlapping between the technical reality and the physical reality. Indeed, the same physical matter (e.g., glass) can provide distinct technical means (resistant, sharp, transparent, etc.) and, inversely, the same technical mean (e.g., resistant) can be provided by distinct physical matters (wood, metal, plastic, etc.). Furthermore, the same 
physical matter does not always provide the technical mean suitable for an intended action since, for instance, the lead of a pencil is friable when applied to paper but not to leather. In sum, technical means are abstract principles acquired with experience and they are not linked with any specific object representation.

The ability to "recognize"/"identify" technical means from physical matter is the first of the two principles of technical reasoning. Le Gall (1998) argued that patients who are impaired in this aspect show the inability to select from several objects the ones whose physical properties are most suited to perform the intended action. More precisely, objects are no longer distinguishable on the basis of the technical means they provide and, as a consequence, the actions undertaken by these patients can be unrecognizable. The description made by Le Gall (1998) coincides with what is more commonly called "errors of content", "perplexity", "object misuse errors" or "mislocation errors" (Buxbaum et al., 1997; De Renzi and Lucchelli, 1988; Morlaas, 1928; Ochipa et al., 1989).

The originality of Gagnepain's (1990) theoretical framework lies in the assumption that technical reasoning is not only founded on the ability to identify, but also on the ability to combine technical means. Indeed, cutting does not only require the opposition between dense and permeable material, but also, for instance, the opposition of two solid materials, since otherwise it would not be the task of cutting, but of carving, cleaving or sculpting. Importantly, the ability to combine might be at the origins of technical progress. Thus, by combining elongate material with materials having characteristics suitable for cutting, early hominids might have designed knives, that is, one of the first technical devices consisting of a handle and, as a result, using a lever-type action (Leroi-Gourhan, 1971, 1973). Le Gall (1998) reported that patients who are impaired in this aspect can forget to carry out an action necessary for completing the task or can perform actions in an awkward and ineffectual way, because the different technical means provided by the objects are no longer combined (e.g., 
the patient holds and uses the blade of a knife for cutting). These patients can also use an object with a missing part as if the object is entire. Le Gall (1998) reported observations of patients who continued to "drive" a screw with a screwdriver even when the blade had been removed (see also Osiurak et al., 2007). These descriptions coincide with what is more commonly called “omission" or "sequence errors" (De Renzi and Lucchelli, 1988; Schwartz et al., 1991; Truelle et al., 1995).

A key assumption of the technical reasoning model is that the reasoning, which determines the technical means (e.g., tracing) appropriate for performing the desired activity (writing), is abstract in that it is not based upon any object representation. Thus, once the technical analysis is completed (e.g., tracing in using friable versus "porous" material), the mental product is only then reified into physical objects available either in the immediate environment or in non-immediate environments (Gagnepain, 1990; Le Gall, 1998; Sabouraud, 2006; for discussion on this issue, see Osiurak et al., 2008b). In this frame, conceptual knowledge would not support the use of objects, but it would play a primary role in enabling individuals to reify the product of technical reasoning outside of the immediate environment (e.g., knowing that friable material can be found inside pencil cases). Likewise, this account assumes that the "motion" carried out by the objects during their use would be constrained by the product of technical reasoning, thus dismissing the existence of gesture engrams at this level.

We think that the technical reasoning model can open perspectives to explain object use impairment. The aim of the present paper was to test the predictions derived from this model and confront them with the predictions made by other hypotheses accounting for impairment of object use. For this purpose, we analyzed the relationship between retrieval of conceptual knowledge about object function, pantomime of object use, recognition of object utilization gestures and conventional use of objects in LBD patients. We also developed the Unusual Use 
of Objects Test, which demands unusual applications of familiar objects to achieve a purpose for which the usually applied object is not provided (e.g., hammering a nail with pliers). The design of this test was based on the assumption that the use of familiar objects in an unusual way probes the capability to infer function from structure (Bozeat et al., 2002; Goldenberg and Hagmann, 1998; Hodges et al., 2000) or technical reasoning (Le Gall, 1998).

First, the gesture engram hypothesis predicts the association between pantomime of object use, recognition of object utilization gestures, and conventional use of objects (Liepmann, 1920). The second prediction derived from the conceptual knowledge hypothesis is that there should be an association between conceptual knowledge and conventional use of objects (De Renzi and Lucchelli, 1988; Ochipa et al., 1989). Third, the direct inference hypothesis predicts that both conceptual knowledge and unusual use of objects correlate with conventional use of objects (Goldenberg and Hagmann, 1998). The fourth prediction derived from the technical reasoning hypothesis is that conventional use of objects should be correlated only with unusual use of objects (Le Gall, 1998).

Besides, the Unusual Use of Objects Test was also designed to assess whether the two technical disturbances postulated by the technical reasoning model can be observed. All objects of this test consisted of an instrumental part (e.g., the blade of a hammer) and a handle. As mentioned above, patients with the inability to identify technical means were expected, in this test, to produce a large number of "action errors" (i.e., the action performed with the object is inappropriate/unrecognizable). By contrast, patients with the inability to combine technical means were expected to produce a large number of "object errors" (i.e., the action is correct but carried out with the wrong part of the object). Performance of these patients could be guided by partial combination of technical means (see above). Nevertheless, this kind of behaviour is unlikely to occur if the instrumental part of the object has to be used with the recipient ${ }^{1}$. Indeed, it can be reasonably supposed that, in the presence of technical 
disturbance, perceptual affordance can guide patients to grasp the handle and, as a consequence, to use the instrumental part with the recipient ${ }^{2}$. For this reason, one third of the actions to be performed in the Unusual Use of Objects Test required to use the instrumental part of the object with the recipient ("instrumental-part" items; e.g., driving a screw into a wooden board with the blade of a knife), a second third required to use the handle of the object with the recipient ("handle" items; e.g., pounding a nail with the handle of a screwdriver), and the last third were impossible actions ("impossible" items; e.g., cutting a metal wire with a corkscrew). We expected that this experimental manipulation would increase the likelihood of obtaining object errors and, thereby, of observing possible impairment in combining technical means.

There is evidence supporting the involvement of right hemisphere in the application but not in the selection of novel tools (Goldenberg and Hagmann, 1998; but for different results, see Hartmann et al. 2005). To further explore this issue, right brain-damaged (RBD) patients were also examined.

\section{METHOD}

\subsection{Participants}

A consecutive series of 20 LBD patients, 11 RBD patients and 41 healthy controls participated in the study. All but 3 subjects ( 3 controls) were right-handed as determined by a screening interview. All patients had suffered a first unilateral cerebral vascular accident (CVA). All participants had no previous history of neurological or psychiatric illnesses. Informed consent was obtained from all subjects, and the study was conducted in accordance with the Declaration of Helsinki.

\subsection{Clinical assessment}

Presence and severity of hemiparesis were rated by the treating physiotherapists. The presence of hemianopia was verified by perimetry in all patients in whom history or clinical 
examination pointed to visual field defects. The presence of hemi-neglect was rated for all patients by combining observation of everyday behaviour with results from tests of linebisection, cancellation and copying. Language assessment was carried out with the MT-86 $\beta$ Aphasia Battery (Nespoulous et al., 1992). It consists of an evaluation of spontaneous speech and of subtests (naming, oral and written comprehension, repetition, and writing). Thirteen out of 20 LBD patients had aphasia which was classified as global in 2, Wernicke in 7, and Broca in 4. The Token Test was used for assessing the general severity of aphasia (De Renzi and Faglioni, 1978).

Table 1 shows demographic and clinical data. There were no significant differences of age, gender, type of CVA, time since CVA, severity of hemiparesis and presence of hemianopia between groups. Hemi-neglect was more frequent in RBD than in LBD patients. LBD patients achieved more years of education than RBD patients ${ }^{3}$.

Table 1 about here

\subsection{Lesion analysis}

Clinical MRI and/or CT scans were available for 26 of 31 patients (16 LBD and 10 RBD). Lesion location was segmented and interpreted by experienced neurologists (F.E.-B., I.R., and I.B.) using the templates of Damasio and Damasio (1989). The templates of the lesions of 16 LBD patients and 10 RBD patients are shown in Fig. 1 and Fig. 2.

\section{Fig. 1 and Fig. 2 about here}

\subsection{Experimental tests}

\subsubsection{Conventional use of objects}

Ten familiar objects (hammer, screwdriver, key, scissors, bottle opener, spoon, saw, cigarette lighter, knife and spanner) and their corresponding recipients (nail, screw, padlock, sheet of paper, bottle, yoghurt pot, piece of wood, candle, slice of bread, and nut on bolt, 
respectively) were placed in front of the subject. Recipients were adapted as to enable a onehanded performance. For example, the nail to hammer upon was fixed in a piece of wood. Subjects were asked to grasp the object and to demonstrate how they use it. Performance was rated on a 3-point scale $(0,1$ and 2$)$. Two points were given if the subject demonstrated the correct utilization of the object with the recipient. One point was given if the correct use was found after unsuccessful trials or if the performance was clumsy (e.g., the subject first attempts to turn the key to open the padlock while the key is not sufficiently driven in). No point was given if the action was not at all achieved (see De Renzi et al., 1968; Goldenberg and Hagmann, 1998). Maximum score was 20 points.

\subsubsection{Pantomime of object use}

This test consisted of a series of 7 pantomimes of object use (using a hammer, screwdriver, saw, scissors, key, spoon, and knife) that the examiner performed slowly in front of the patient for her/him to reproduce immediately afterwards. Each item was scored by the examiner on a 3 -point scale: $0=$ unable/gross errors; $1=$ possible errors; $2=$ correct $($ see Kimura and Archibald, 1974; Sunderland and Sluman, 2000). Maximum score was 14 points.

\subsubsection{Recognition of object utilization gestures}

This test (Bergego et al., 1992) consisted of 20 sets of four photographs. In each set, one photograph depicted the correct use of the object, whereas the remaining three photographs showed the object incorrectly oriented, inappropriately held or used as another object. One point was credited for each correct response, totalling 20 points.

\subsubsection{Conceptual knowledge}

\subsubsection{Functional picture matching.}

Subjects completed two subtests of the Visual Gnosis Battery (Agniel et al., 1992), each consisting of 10 trials. Subjects were asked to choose one of the three response alternatives as the best match to the target. Each subtest was preceded by two practice trials for which 
feedback on the correctness was given. In the associative condition, the target (e.g., screw) and the correct response (screwdriver) were functionally associated. In the categorical condition, the target (e.g., belt) and the correct response (pair of shoulder straps) were functionally equivalent. A score of 1 point was credited if the correct response was given in 30 seconds, totalling a maximum score of 10 points for each condition.

\subsubsection{Alternative object selection}

Subjects also performed the Alternative Object Selection Test (Le Gall et al., 2000) in which they were asked to select from a list of four words, via pointing, the name of the object that could be used for carrying out the action spoken by the examiner ("With which of these objects can you comb your hair?"). The test consisted of 10 sets of four words. In each set, one word corresponded to an object (e.g., fork) sharing critical physical features of the familiar object (comb) used to perform the intended action (combing hair). The remaining three foils were chosen to be either visually similar to, from the same category as, or unrelated with, the target (e.g., brush, toothpaste, watch, respectively). Scoring of each item was binary (0 or 1 ), and thus the maximum score was 10 points.

\subsubsection{Unusual use of objects}

\subsubsection{Materials and procedure}

Subjects were asked to execute 24 actions (hereafter referred to as "items"), each involving an object and a recipient. The different items are summarized in Table 2. Recipients were adapted as to enable a one-handed performance. Each object consisted of a handle and an instrumental part (e.g., the blade of a knife). Subjects were informed that they would have to use familiar objects in an unusual way and that they would be required to show how the action can be achieved by acting with the given object. Nonetheless, if the action was considered as impossible, subjects were asked to point to a card on which "NO" was printed. Instructions for the action to be performed (e.g., "divide the sheet of paper in half") were spoken aloud 
and printed on white paper. Two photographs depicting the given action (a whole sheet of paper - two half sheets) were also presented to ensure that the instructions were fully understood by aphasic patients. The test was preceded by four practice items for which feedback on the correctness was given. If necessary, subjects were helped to achieve the action.

Table 2 about here

There were three categories of items (see Fig. 3). Instrumental-part items corresponded to items in which the instrumental part of the object had to be brought in contact with the recipient in order to achieve the action (e.g., driving a screw with the blade of a knife). Handle items were items in which the handle of the object had to be brought in contact with the recipient in order to achieve the action (e.g., eating yoghurt with the handle of a fork). Impossible items corresponded to items in which neither the instrumental part, nor the handle of the object was appropriate to achieve the action (e.g., sawing a piece of wood with a spoon). Each category consisted of 8 different items (see Table 2). The series of 24 items was presented a second time after a 5-min rest period in order to prevent any effect due to the orientation of objects. Each object was thus presented with the handle alternately oriented to left or right. In sum, each category consisted of 16 items giving a total of 48 items.

Fig. 3 about here

\subsubsection{Data analysis}

Three types of responses could be distinguished. Responses were rated as instrumentalpart responses if the instrumental part of the object was brought in contact with the recipient in order to achieve the action. The use of the handle with the recipient was rated as handle response. Responses were rated as impossible responses when the card "NO" was pointed to. 
Effectiveness of responses was assessed separately. Each recipient required a specific action so that any other action was rated as action error (e.g., sawing the yoghurt pot with the saw). Responses were rated as object errors when the action performed with object was appropriate, but carried out with the wrong part of the object (e.g., pounding a nail with the blade of the knife). Impossible responses made in instrumental-part and handle items were rated as incorrect impossible responses. Finally, correct responses were recorded either if the action was carried out with the expected part of the object, or if the card "NO" was pointed to in impossible items.

\subsubsection{Normative study with healthy control subjects}

\subsection{Item analysis}

The aim of this analysis was to ascertain whether agreement existed between the expected responses and those made by healthy controls (see Table 2). Healthy subjects produced more than $90 \%$ of instrumental-part responses in each of the instrumental-part items (mean consistency of $95 \%$ ) and more than $70 \%$ of handle responses in each of the handle items (mean consistency of $81 \%$ ). The mean consistency of impossible items was $82 \%$. On the whole, the responses made by controls agreed closely with the expected responses (general mean consistency of $86 \%$ ).

\subsection{Effects of demographics}

The effects of age, gender and education level on the number of instrumental-part, handle and impossible responses, and on the number of correct responses, object errors, action errors and incorrect impossible responses were examined. None of these variables had a statistically significant effect.

\subsection{Statistical analysis}

Because of unequal group sizes and partly unequal variances, non-parametric tests were preferred. Between-group comparisons were performed with Kruskal-Wallis non-parametric 
one-way ANOVAs and with Mann-Whitney $U$-tests. When Kruskal-Wallis ANOVAs were significant, these were followed by post-hoc comparisons using Mann-Whitney $U$-tests. Wilcoxon signed-rank tests were used for within-group comparisons. Spearman rank order correlations were used to study relationships between variables. Because of the number of comparisons computed, a stringent alpha level $(p=.01)$ was selected to reduce the possibility of type I error.

One purpose of this study was to examine whether different forms of technical disorders could be detected in the Unusual Use of Objects Test. Therefore, for the distribution of instrumental-part, handle and impossible responses, many comparisons were conducted using "a case-study" model in which each patient's individual data were compared to a control mean (for a similar procedure, see Buxbaum et al., 2003). The average (mean) control distribution of instrumental-part, handle and impossible responses was compared to the distribution of each brain-damaged patient by $\chi^{2}$ analysis. Moreover, effectiveness of responses (correct responses, action errors, object errors and incorrect impossible responses) was analyzed separately for each brain-damaged patient. The cut off was established as the worst score achieved by the controls participating in the present study. Given our particular interest in exploring the ratio of object and action errors in brain-damaged patients, the Revised Standardized Difference Test (RSDT; Crawford and Garthwaite, 2005) was computed to detect dissociations in which a patient made more object than action errors, or vice versa.

\section{RESULTS}

All brain-damaged patients used their ipsilesional hand in order to prevent any effect due to motor or sensory impairment. Eighteen controls used their right hand and 23 their left hand. Since no difference emerged in the use of either hand, the scores of the two control subgroups were pooled together. Four RBD patients showed pronounced difficulties in identifying line 
drawings and photographs of objects and, as a result, were not asked to complete the Functional Picture-Matching Test and the Recognition of Object Utilization Gestures Test. Because of severe difficulties in understanding written language, 3 LBD patients were not asked to perform the Alternative Object Selection Test.

\subsection{Comparisons between groups}

\subsubsection{Conceptual knowledge, pantomime of object use, recognition of object utilization} gestures, and conventional use of objects

Table 3 gives an overview of results on the experimental tests. Kruskal-Wallis ANOVAs with the between-subject factor group (LBD, RBD, Control) were carried out separately for each test. They disclosed significant effects of group for each test ( $H$ values between 9.75 and 25.59 , all $p s<.002$ ) with the exception of the associative condition of the Functional PictureMatching Test. Post hoc testing was performed with Mann-Whitney $U$-tests. LBD patients scored significantly lower than controls on all tests. RBD patients had significantly poorer scores than controls on the Alternative Object Selection Test and on the Recognition of Object Utilization Gestures Test. Differences between LBD and RBD patients were nonsignificant.

Table 3 about here

\subsubsection{Unusual use of objects}

Table 3 shows the distribution of instrumental-part, handle and impossible responses. Kruskal-Wallis ANOVAs with the between-subject factor group (LBD, RBD, Control) were run for each measure. An effect of group was observed for the number of instrumental-part responses $(H=13.24, p=.001)$. Post hoc pairwise comparisons indicated that LBD patients demonstrated a higher number of instrumental-part responses than either RBD patients or controls. The latter two groups did not differ significantly from each other. Between-group 
differences were not found for the number of handle responses or for the number of impossible responses.

The distribution of correct responses, action errors, object errors and incorrect impossible responses is shown in Table 3. Kruskal-Wallis ANOVAs with the between-subject factor group (LBD, RBD, Control) disclosed no differences between groups for the number of object errors and for the number of incorrect impossible responses ( $H$ values of 8.64 and 0.29 , both $p s>.03)$. There was an effect for the number of correct responses $(H=20.99, p=.001)$. Post hoc testing revealed that LBD patients had a lower number of correct responses than either RBD patients or controls. RBD patients and controls did not differ. An effect was also found for the number of action errors $(H=25.83, p=.001)$. Post hoc pairwise comparisons indicated that LBD patients showed a higher number of action errors than RBD patients and controls. The difference between RBD and controls did not reach significance.

\subsection{Correlations between test results in LBD patients}

Because of the ceiling effects in controls and RBD patients, correlations of test results were analyzed only in LBD patients. The score of severity of aphasia assessed with the Token Test was also included in correlational analyses to evaluate the possible influence of aphasia on test performances. Table 4 gives an overview of correlations. Spearman rank order correlations revealed a strong association between conventional use of objects and unusual use of objects. Pantomime of object use was correlated with none of the other variables. A significant association was found between the recognition of object utilization gestures and the conventional use of objects. It is noteworthy that correlations between tests assessing conceptual knowledge (both conditions of the Functional Picture-Matching test and alternative object selection) and object use (conventional use of objects and unusual use of objects) did not reach statistical significance. Aphasia severity was associated with 
conventional use of objects, unusual use of objects and the categorical condition of the Functional Picture-Matching Test.

Table 4 about here

To further explore the correlational structure of test results in LBD patients, the correlational matrix of all experimental tests was subjected to multidimensional scaling using SPSS procedure ALSCAL. Multidimensional scaling yields a graphical representation of the correlational structure (Young, 1987; see Goldenberg et al., 2003). Higher correlations are represented by smaller distances between the respective data points. The distances correspond to the rank order of the correlations but not necessarily to their absolute values.

ALSCAL achieved a satisfactory two-dimensional representation (Kruskal's stress $=0.01$, $\left.r^{2}=0.99\right)$ which is displayed in Fig. 4. The spatial distribution of the experimental tests can be interpreted as being ordered along two dimensions. One, oriented horizontally, goes from tests of object use (conventional use of objects and unusual use of objects) on the left side, via the Recognition of Object Utilization Gesture Test, to tests of conceptual knowledge and pantomime of object use. The other one, oriented vertically, opposes aphasia severity to all other measures.

Fig. 4 about here

\subsection{Individual analysis of performance for the Unusual Use of Objects Test}

A detailed description of performance obtained by each brain-damaged patient in the Unusual Use of Objects Test is shown in Table 5. Performance of the Conventional Use of Objects Test is also reported. As can be seen, all patients who encountered difficulties in using familiar objects fell below the cut-off of the Unusual Use of Objects Test (number of correct responses), confirming the strong correlation found between the two variables. Note that none of the RBD patients scored below the cut-off on either test. 
Table 5 about here

\subsubsection{Types of responses}

For the distribution of instrumental-part, handle and impossible responses, many comparisons were conducted using "a case-study" model in which each patient's individual data were compared to the controls' mean $^{4}$ (the mean values of controls are given in Table 3). As can be seen in Table 5, there were 10 patients whose response distribution differed from that of controls. Among them, 8 LBD patients (L05, L06, L07, L08, L09, L10, L11 and L15) differed because of a relatively low number of handle responses. All these patients but one (L15) scored below the cut-off for the number of correct responses. Patients L16 and R01 showed a somewhat similar pattern in giving a relatively low number of impossible responses. Their number of correct responses was normal.

Two other important results have to be mentioned. Firstly, despite some difficulties in performing the Unusual Use of Objects Test, 4 LBD patients (L01, L02, L03 and L04) behaved in a comparable manner to controls for the distribution of instrumental-part, handle and impossible responses. Secondly, on the whole, brain-damaged patients produced a significant number of impossible responses since only 4 patients (L06, L10, L16 and R01) fell below the cut-off for this variable. These results demonstrate that patients took the opportunity it offered them to reject some items, confirming that, on the one hand, task instructions were understood and, on the other hand, incorrect "non-impossible" responses made by patients were well guided by the will to demonstrate how the given object could be used with the recipient.

\subsubsection{Effectiveness of responses}

As shown in Table 5, almost all LBD patients who fell below the cut-off for the number of correct responses scored below the cut-off for the number of action errors. By contrast, only 4 LBD patients (L04, L06, L10 and L11) made an abnormally high number of object errors. We 
used RSDT method (Crawford and Garthwaite, 2005) to detect dissociations in which a patient made more object than action errors, or vice versa. This analysis revealed that none of the LBD or RBD patients made a significantly higher number of object errors. By contrast, 5 LBD patients (L07, L08, L09, L10 and L11) produced a relatively higher number of action errors (all $p s<.01)$. These results are consistent with the between-group differences found for action but not for object errors. This can largely be attributed to the greater number of object than action errors committed by controls $(p<.001$, Wilcoxon signed-rank Test; see also Table $3)$.

In sum, individual analysis enables the detection of two performance profiles, that is, the Profile A, which corresponds to patients L01, L02, L03 and L04 who, despite some difficulties in performing the Unusual Use of Objects Test, behaved in a comparable manner to controls for the distribution of instrumental-part, handle and impossible responses, and the Profile B, which corresponds to patients L05, L06, L07, L08, L09, L10 and L11 who, besides poor performance in the Unusual Use of Objects Test, produced a relatively low number of handle responses.

\section{DISCUSSION}

The aim of the present paper was to test the predictions derived from the technical reasoning hypothesis and confront them with the predictions made by the gesture engram hypothesis, the conceptual knowledge hypothesis and the direct inference hypothesis. The key findings of our study are the dramatically high association between the ability to demonstrate the conventional use of objects and the unusual use of objects. These results support the technical reasoning model. Before discussing these findings further, we will first turn our attention to the other hypotheses examined in the present paper. 


\subsection{The gesture engram hypothesis}

In Liepmann's conception of apraxia (Liepmann, 1920), difficulties with skilled object use are attributable to damage to gesture engrams. Several subsequent investigators have questioned this proposal, suggesting rather that the integrity of gesture engrams would bear upon the integrity of gesture production and recognition (Buxbaum, 2001; Cubelli et al., 2000; Rothi et al., 1991). Support for this view is provided by evidence that knowledge of object manipulation (i.e., gesture engrams) can dissociate from knowledge of object function (Buxbaum et al., 2000; Buxbaum and Saffran, 2002; Sirigu et al., 1991). Although this recent literature led us to expect that difficulties in using familiar objects would not be strongly related to gesture recognition, our results are not consistent with this expectation, supporting instead Liepmann's hypothesis in that there is no need to postulate two separate components of knowledge to explain object use. Nonetheless, the high correlation we found between the ability to demonstrate the conventional use of objects and the unusual use of objects questions the idea that difficulties stem from the inability to store or access gesture representations.

In accordance with the technical reasoning model (Gagnepain, 1990; Le Gall, 1998), we suggest that all situations in which objects have to be "used" (i.e., actual use of objects in a conventional - or unusual - way, pantomime, gesture recognition) might share the common ability to perform technical reasoning. This proposal is not inconsistent with the idea that each of these situations would require additional cognitive processes, such as, in the instance of pantomime, the creation of a mental image (Goldenberg et al., 2003; Roy and Hall, 1992). Importantly it might be, precisely, the significant portion of patients having damage to these specific and additional cognitive processes which would modulate the strength of association between these different situations of object use. As regards the present study, this could explain why, unlike previous works, we did not report any relationship between pantomime of object use and recognition of object utilization gestures or between pantomime of object use 
and conventional use of objects $^{5}$ (for significant association between pantomime and object use, see Goldenberg and Hagmann, 1998; Osiurak et al., 2008a; for significant association between gesture recognition and production, see Buxbaum et al., 2005b).

\subsection{The conceptual knowledge hypothesis}

Several patients have been described in the literature who were unable to use objects correctly despite having preserved knowledge about those same objects (Buxbaum et al., 1997; Moreaud et al., 1998; Negri et al., 2007; Rumiati et al., 2001). In line with these reports, we did not find any significant correlation between conceptual knowledge and object use, thereby supporting the dissociation between knowing the purpose for which objects have been made and knowing the way in which they should be used to achieve that purpose.

These conclusions appear inconsistent with recent works by Hodges et al. (2000; see also Bozeat et al., 2002) on semantic dementia, in which deficits in the use of isolated objects in line with the patients' conceptual impairment was shown. However, while these studies have provided strong evidence for the key role played by conceptual knowledge in object use, it has also been emphasized that this conclusion would mainly apply to the use of objects in isolation. In particular, patients with semantic dementia show an advantage for object use with the recipient present. Bozeat et al. (2002) hypothesized that the presence of a recipient might benefit the patients' object use by providing a level of context and, therefore, access to further conceptual knowledge. Thus, even in the context of degraded conceptual knowledge, two mildly impoverished representations (for the object and its recipient) may still be sufficient to constrain object use. Our findings, with regard to the correlations between conceptual knowledge and actual use of objects, question this conclusion. Another possibility, which is more consistent with our results, is that demonstrating the use of an isolated object requires specifying its usual purpose (in which context it is used, with which kind of objects) to then reason about the technical means it provides. However, the role played by conceptual 
knowledge would be considerably reduced as soon as the entire "mechanical device" is given, such as in the context of the use of objects with their recipients. In this case, technical reasoning could be sufficient to support the utilization (for discussion on this issue, see Osiurak et al., 2008b).

\subsection{The direct inference hypothesis}

Given the growing literature reporting patients with good object use in the face of degraded conceptual knowledge, and vice versa, attention has been turned to the idea that object use might be based on a direct inference of function from structure. Consistent with this, we observed that all patients who had difficulties demonstrating the use of familiar objects in a conventional way were also unable to use objects in an unusual way. However, the direct inference hypothesis also predicts that success in object use is related with level of conceptual deficit, which is inconsistent with the present results.

\subsection{The technical reasoning hypothesis}

As mentioned in the Introduction, the technical reasoning model may open new perspectives by suggesting that object use skills depend solely on the ability to perform reasoning about technical means. This model is supported by the dramatically high association between the ability to demonstrate the conventional use of objects and the unusual use of objects as well as by the absence of any significant correlation between unusual use of objects and the other experimental variables.

Another key finding of the present study concerns the way in which patients with the Profile B behaved in the Unusual Use of Objects Test. Besides the difficulties in performing this test, these patients grasped the object by the handle and then brought the instrumental part in contact with the recipient. It can reasonably be suggested that these patients maintained the ability to detect the affordances provided by the handle. Many authors have considered that object use could be supported by affordances (Bozeat et al., 2002; Buxbaum et al., 1997; 
Gibson, 1979; Hodges et al., 2000; Sirigu et al., 1991; van Leeuwen et al., 1994; Wagman and Carello, 2001, 2003). With regard to the low number of correct responses made by patients with the Profile B in the Unusual Use of Objects Test, this hypothesis is not confirmed here. We rather suggest that this performance profile provides evidence for two distinct levels of action: Affordances, which are critical to detect user-environment complementarities but not to use objects, and technical reasoning, which supports solely the use of objects.

One purpose of the present study was to examine the possibility that defective use of familiar objects might result from two different forms of technical disorders (identity versus combination). For this aim, we designed the Unusual Use of Objects Test and we hypothesized two error profiles. On the one hand, patients with the inability to identify technical means were expected to commit more action than object errors and, on the other hand, patients with the inability to combine technical means were expected to commit more object than action errors. We found five LBD patients who produced more action than object errors. Nevertheless, the unexpectedly high number of object errors made by controls did not allow us to conclude on this point, besides suggesting that the ratio of object and action errors is not a relevant criterion to differentiate between the two hypothetical forms of technical disorders.

It is also important to note that the performance of LBD patients with the Profile A is an intriguing result that is not easy to interpret. Indeed, despite some difficulties in performing the Unusual Use of Objects Test, these patients behaved in a comparable manner to controls and RBD patients. Furthermore, all these patients but one (L02) performed within the normal range of controls on the Conventional Use of Objects Test. It can be supposed that their technical impairment was too mild to be detected by the Unusual Use of Objects Test. Another possibility that must be considered is that the severity of aphasia played an important 
role in the performance of the Unusual Use of Objects Test, which is consistent with the results of correlational analyses. Thus, language abilities of these four LBD patients could be better preserved than in those of the Profile B, suggesting that task instructions may have not been fully understood by some LBD patients. There are two lines of evidence demonstrating that is unlikely to have been the case. First, multidimensional scaling of the correlational structure revealed that there was a clear separation between aphasia severity placed on the extremity of the representation and unusual use of objects on the other. Second, our results indicated that LBD patients used in a comparable manner to RBD patients or controls the possibility to reject some items, confirming that task instructions were well understood. In sum, we did not find any convincing explanation for the unexpected performance profile of these four patients. However, these intriguing results remain an unresolved issue that motivates our continuing research.

In summary, we think that the Unusual Use of Objects Test might be particularly sensitive to marked technical disorders (Profile B) because it requires individuals to behave "in contradiction" with what affordances provide. It is noteworthy that, thanks to this test, some patients (L05, L08 and L09) showed a certain technical disorder in attempting, for instance, to hammer a nail with the blade of a knife, while their relatively "good" performance on the Conventional Use of Objects Test (Table 5) could have led to conclude that they had no severe difficulty in using objects.

\subsection{Influence of right hemisphere damage}

Although left hemisphere dominance has been clearly established for use of familiar objects in the context of clinical assessment, there is some evidence that RBD patients can be impaired when asked to use, but not select, novel tools (Goldenberg and Hagmann, 1998; but for different results, see Hartmann et al., 2005). One of our purposes was to clarify these controversial findings. In the present study, RBD patients did not encounter any difficulty 
either in selecting the correct part of objects, or in using it with recipients. Only one RBD patient (R01) had an "atypical" profile in the Unusual Use of Objects Test, in making an abnormally low number of impossible responses. However, this profile was also found in one LBD patient (L16), suggesting that such behaviour is not specifically attributable to right hemispheric damage. Given that these two patients (R01 and L16) had circumscribed lesions in the medial prefrontal region, we hypothesize that the manner in which they behaved in the Unusual Use of Objects Test could evidence the presence of frontal signs such as utilization behaviour (Lhermitte, 1986; Shallice et al., 1989).

\section{CONCLUSION}

The technical reasoning model originally developed by Gagnepain (1990) importantly reminds us that human beings are unique in that they are able to perform reasoning about technical means provided by objects. Although we acknowledge that the present findings are not sufficient to fully support this perspective, we think that this theoretical framework can open new perspectives in the understanding of object use impairment. This is not to say that all the difficulties encountered by brain-damaged patients in activities requiring object use can be attributed solely to an impaired technical reasoning. As Hodges et al. (2000) clearly demonstrated, conceptual knowledge may play a key role when objects have to be used in isolation (see also Bozeat et al., 2002). Similarly, performing everyday activities may call upon specific cognitive processes that would not be critical for good performance in clinical tests of object use. Indeed, some activities such as coffee making can be decomposed into a set of separate technical actions (filtering, containing, etc.) that must be combined. Technical reasoning enabling this combination is supposed to be abstract and, as a result, without time constraints. Nevertheless, when executed, the activity does not always involve the presence of the individual (e.g., waiting for the coffee to brew) so that time can be employed to carry out other activities (e.g., turning on the computer). The ability to organize time refers to planning 
skills that have been shown to be particularly impaired in patients with prefrontal injuries (Shallice, 1982; Shallice and Burgess, 1991). Importantly while, in these patients, serious difficulties in performing two everyday activities simultaneously have been found, each activity when executed in isolation is generally well achieved, confirming that difficulties do not stem from the inability to perform technical reasoning (see Goldenberg et al., 2007). This last example shows, once more, that the technical reasoning model may be particularly useful in delineating the roles played by the different cognitive processes (technical reasoning, conceptual knowledge, time management) during object use. 


\section{REFERENCES}

Agniel A, Joanette Y, Doyon B, and Duchein C. Protocole Montréal-Toulouse d'évaluation des gnosies visuelles. Isbergues: L'Ortho-Edition, 1992.

Bartolo A, Daumüller M, Della Sala S, and Goldenberg G. Relationship between objectrelated gestures and the fractionated object knowledge system. Behavioural Neurology, 18: 143-147, 2007.

Bergego C, Pradat-Diehl P, Deloche G, Durand E, and Lauriot-Prevost MC. Apraxie idéatoire et reconnaissance de l'utilisation des objets. Revue de Neuropsychologie, 2: 193-206, 1992.

Bozeat S, Lambon Ralph MA, Patterson K, and Hodges JR. When objects lose their meaning: What happens to their use? Cognitive, Affective, and Behavioral Neurosciences, 2: 236-251, 2002.

Buxbaum LJ. Ideomotor Apraxia: A call to action. Neurocase, 7: 445-448, 2001.

Buxbaum LJ, Johnson-Frey SH, and Bartlett-Williams M. Deficient internal models for planning hand-object interactions in apraxia. Neuropsychologia, 43: 917-929, 2005 a.

Buxbaum LJ, Kyle KM, and Menon R. On beyond mirror neurons: Internal representations subserving imitation and recognition of skilled object-related actions in humans. Cognitive Brain Research, 25: 226-239, 2005b.

Buxbaum LJ and Saffran EM. Knowledge of object manipulation and object function: Dissociations in apraxic and nonapraxic subjects. Brain and Language, 82: 179-199, 2002.

Buxbaum LJ, Schwartz MF, and Carew TG. The role of memory in object use. Cognitive Neuropsychology, 14: 219-254, 1997.

Buxbaum LJ, Sirigu A, Schwartz MF, and Klatzky R. Cognitive representations of hand posture in ideomotor apraxia. Neuropsychologia, 41: 1091-1113, 2003. 
Buxbaum LJ, Veramonti T, and Schwartz MF. Function and manipulation tool knowledge in apraxia: Knowing "what for" but not "how". Neurocase, 6: 83-97, 2000.

Crawford JR and Garthwaite PH. Testing for suspected impairments and dissociations in single-case studies in neuropsychology: Evaluation of alternatives using Monte Carlo simulations and revised tests for dissociations. Neuropsychology, 19: 318-331, 2005.

Cubelli R, Marchetti G, Boscolo S, and Della Sala S. Cognition in action: Testing a model of limb apraxia. Brain and Cognition, 44: 144-165, 2000.

Damasio $\mathrm{H}$ and Damasio AR. Lesion analysis in neuropsychology. New York: Oxford University Press, 1989.

De Renzi E and Faglioni P. Normative data and screening power of a shortened version of the Token Test. Cortex, 14: 41-49, 1978.

De Renzi E and Lucchelli F. Ideational apraxia. Brain, 111: 1173-1185, 1988.

De Renzi E, Pieczuro A, and Vignolo LA. Ideational apraxia: A quantitative study. Neuropsychologia, 6: 41-52, 1968.

Gagnepain J. Du vouloir dire: Du signe, de l'outil. Paris: Livre et Communication, 1990.

Gibson JJ. The ecological approach to visual perception. Boston: Houghton Mifflin, 1979.

Goldenberg $G$ and Hagmann S. Tool use and mechanical problem solving in apraxia. Neuropsychologia, 36: 581-589, 1998.

Goldenberg G, Hartmann K, and Schlott I. Defective pantomime of object use in left brain damage: Apraxia or asymbolia? Neuropsychologia, 41: 1565-1573, 2003.

Goldenberg G, Hartmann-Schmid K, Sürer F, Daumüller M, and Hermsdörfer J. The impact of dysexecutive syndrome on use of tools and technical devices. Cortex, 43: 424-435, 2007.

Goldenberg G, Hentze S, and Hermsdörfer J. The effect of tactile feedback on pantomime of tool use in apraxia. Neurology, 63: 1863-1867, 2004. 
Goldenberg G and Iriki A. From sticks to coffee-maker: Mastery of tools and technology by human and non-human primates. Cortex, 43: 285-288, 2007.

Goodale MA, Meenan JP, Bülthoff H, Nicolle DA, Murphy KJ, and Racicot CI. Separate neural pathways for the visual analysis of object shape in perception and prehension. Current Biology, 4: 604-610, 1994.

Hartmann K, Goldenberg G, Daumüller M, and Hermsdörfer J. It takes the whole brain to make a cup of coffee: The neuropsychology of naturalistic actions involving technical devices. Neuropsychologia, 43: 625-637, 2005.

Heilman KM, Maher LM, Greenwald ML, and Rothi LJG. Conceptual apraxia from lateralized lesions. Neurology, 49: 457-464, 1997.

Heilman KM, Rothi LJ, and Valenstein E. Two forms of ideomotor apraxia. Neurology, 32: 342-346, 1982.

Hermsdörfer J, Hentze S, and Goldenberg G. Spatial and kinematic features of apraxic movement depend on the mode of execution. Neuropsychologia, 44: 1642-1652, 2006.

Hodges JR, Bozeat S, Lambon Ralph MA, Patterson K, and Spatt J. The role of knowledge in object use: Evidence from semantic dementia. Brain, 123: 1913-1925, 2000.

Hodges JR, Spatt J, and Patterson K. "What" and "how": Evidence for the dissociation of object knowledge and mechanical problem-solving skills in the human brain. Proceeding of the National Academy of Sciences of the USA, 96: 9444-9448, 1999.

Johnson-Frey SH. The neural basis of complex tool use in humans. Trends in Cognitive Sciences, 8: 71-78, 2004.

Kimura D and Archibald Y. Motor functions of the left hemisphere. Brain, 97: 337-350, 1974.

Lauro-Grotto R, Piccini C, and Shallice T. Modality-specific operations in semantic dementia. Cortex, 33: 593-622, 1997. 
Le Gall D. Apraxies idéo-motrice et idéatoire: Revue critique de la littérature. Revue de Neuropsychologie, 2: 325-371, 1992.

Le Gall D. Des apraxies aux atechnies: Propositions pour une ergologie clinique. Bruxelles: De Boeck Université, 1998.

Le Gall D, Morineau T, and Etcharry-Bouyx F. Les apraxies: Formes cliniques, modèles théoriques et méthodes d'évaluation. In Seron X, and Van der Linden M (Eds), Traité de neuropsychologie clinique. Marseille: Solal, 2000: 291-310.

Leroi-Gourhan A. L'Homme et la matière. Paris: Michel, 1971

Leroi-Gourhan A. Milieu et techniques. Paris: Michel, 1973.

Lhermitte F. Human autonomy and the frontal lobes. Part 2: The "environmental dependency syndrome”. Annals of Neurology, 4: 335-343, 1986.

Liepmann H. Apraxie. Ergebnisse der gesamten Medizin, 1: 516-540, 1920.

Moreaud O, Charnallet A, and Pellat J. Identification without manipulation: A study of the relations between object use and semantic memory. Neuropsychologia, 36: 1295-1301, 1998.

Morlaas J. Contribution à l'étude de l'apraxie. Paris: Amédée Legrand, 1928.

Negri GA, Lunardelli A, Reverberi C, Gigli GL, and Rumiati RI. Degraded semantic knowledge and accurate object use. Cortex, 43: 376-388, 2007.

Nespoulous JL, Lecours AR, Lafond D, Lemay A, Puel M, Joanette Y, Cot F, and Rascol A. Protocole Montréal-Toulouse d'examen linguistique de l'aphasie MT86. Isbergues: L'Ortho-Edition, 1992.

Ochipa C, Rothi LJG, and Heilman KM. Ideational apraxia: A deficit in tool selection and use. Annals of Neurology, 25: 190-193, 1989.

Ochipa C, Rothi LJG, and Heilman KM. Conceptual apraxia in Alzheimer's disease. Brain, 115: 1061-1071, 1992. 
Osiurak F, Aubin G, Allain P, Jarry C, Etcharry-Bouyx F, Richard I, and Le Gall D. Different constraints on grip selection in brain-damaged patients: Object use versus object transport. Neuropsychologia, 46: 2431-2434, 2008a.

Osiurak F, Aubin G, Allain P, Jarry C, Richard I, and Le Gall D. Object utilization and object usage: A single-case study. Neurocase, 14: 169-183, $2008 \mathrm{~b}$.

Osiurak F, Jarry C, Allain P, Aubin G, Etcharry-Bouyx F, Richard I, and Le Gall D. Des troubles praxiques aux troubles techniques: Une étude de deux cas. Revue de Neuropsychologie, 17: 231-259, 2007.

Rosenbaum DA, Marchak F, Barnes HJ, Vaughan J, Slotta J, and Jorgensen M. Constraints for action selection: Overhand versus underhand grips. In Jeannerod M (Ed), Attention and Performance XIII. Hillsdale: Lawrence Erlbaum Associates, 1990: 321-342.

Rothi LJG, Ochipa C, and Heilman KM. A cognitive neuropsychological model of limb praxis. Cognitive Neuropsychology, 8: 443-458, 1991.

Roy EA and Hall C. Limb apraxia: A process approach. In Proteau L, and Elliott D (Eds), Vision and motor control. Amsterdam: Elsevier Science Publishers, 1992: 261-282.

Rumiati RI, Zanini S, Vorano L, and Shallice T. A form of ideational apraxia as a selective deficit of contention scheduling. Cognitive Neuropsychology, 18: 617-642, 2001.

Sabouraud O. En quête d'une théorie de l'humain. Le Débat, 140: 68-85, 2006.

Schwartz MF, Reed ES, Montgomery MW, Palmer C, and Mayer NH. The quantitative description of action disorganisation after brain damage: A case study. Cognitive Neuropsychology, 8: 381-414, 1991.

Shallice T. Specific impairments of planning. Philosophical Transactions of the Royal Society of London B, 298: 199-209, 1982.

Shallice T and Burgess PW. Deficits in strategy application following frontal lobe damage in man. Brain, 114: 727-741, 1991. 
Shallice T, Burgess PW, Schon F, and Baxter DM. The origins of utilisation behaviour. Brain, 112: 1587-1598, 1989.

Sirigu A, Duhamel JR, and Poncet M. The role of sensorimotor experience in object recognition. Brain, 114: 2555-2573, 1991.

Spatt J, Bak T, Bozeat S, Patterson K, and Hodges JR. Apraxia, mechanical problem solving and semantic knowledge: Contributions to object usage in corticobasal degeneration. Journal of Neurology, 249: 601-608, 2002.

Sunderland A and Sluman SM Ideomotor apraxia, visuomotor control and the explicit representation of posture. Neuropsychologia, 38: 923-934, 2000.

Truelle JL, Le Gall D, Joseph PA, Aubin G, Derouesné C, and Lezak MD. Movement disturbances following frontal lobe lesions: Qualitative analysis of gesture and motor programming. Neuropsychiatry, Neuropsychology and Behavioral Neurology, 8: 14-19, 1995.

van Leeuwen L, Smitsman A, and van Leeuwen C. Affordances, perceptual complexity, and the development of tool use. Journal of Experimental Psychology: Human Perception and Performance, 20: 174-191, 1994.

Wagman JB and Carello C. Affordances and inertial constraints on tool use. Ecological Psychology, 13: 173-195, 2001.

Wagman JB and Carello C. Haptically creating affordances: The user-tool interface. Journal of Experimental Psychology: Applied, 9: 175-186, 2003.

Young FW. Multidimensional scaling: History, theory, and applications. Hillsdale: Lawrence Erlbaum Associates, 1987. 
Table 1.

Demographic and clinical data.

\begin{tabular}{|c|c|c|c|c|c|c|c|}
\hline & $\begin{array}{c}\text { LBD } \\
(\mathrm{n}=20)\end{array}$ & $\begin{array}{c}\text { RBD } \\
(\mathrm{n}=11)\end{array}$ & $\begin{array}{l}\text { Control } \\
(\mathrm{n}=41)\end{array}$ & $\begin{array}{c}\text { All } \\
\text { groups }\end{array}$ & $\begin{array}{l}\text { LBD vs } \\
\text { RBD }\end{array}$ & $\begin{array}{l}\text { LBD vs } \\
\text { Control }\end{array}$ & $\begin{array}{l}\text { RBD vs } \\
\text { Control }\end{array}$ \\
\hline Gender (no.): women/men & $3 / 17$ & $4 / 7$ & $19 / 22$ & ns & - & - & - \\
\hline Age (years) & $58.2(16.3)$ & $66.1(15.6)$ & $61.5(18.2)$ & ns & - & - & - \\
\hline Education (years) & $11.5(3.9)$ & $8.4(2.5)$ & $10.5(3.4)$ & $*$ & $*$ & ns & ns \\
\hline Type of CVA: ischemia/bleeding & $8 / 12$ & $4 / 7$ & - & ns & 一 & - & - \\
\hline Time since CVA (months) & $3.2(3.9)$ & $3.4(1.7)$ & - & ns & - & - & - \\
\hline $\begin{array}{l}\text { Hemiparesis (no.): } \\
\text { none/paresis/plegia }\end{array}$ & $13 / 2 / 5$ & $3 / 2 / 6$ & - & ns & - & - & - \\
\hline $\begin{array}{l}\text { Hemi-neglect (no.): } \\
\text { present/absent }\end{array}$ & $0 / 20$ & $9 / 2$ & - & $* * *$ & - & - & - \\
\hline Hemianopia (no.): present/absent & $3 / 17$ & $0 / 11$ & - & ns & - & - & - \\
\hline Token Test $^{\mathrm{a}}$ & $20.6(10.5)$ & $32(3.1)$ & $34.9(1.5)$ & $* * *$ & $* *$ & $* * *$ & ns \\
\hline
\end{tabular}

Between-group comparisons were performed with $\chi^{2}$ analyses, except for "Age", "Education" and "Token Test" (Kruskal-Wallis ANOVAs), and "Time since CVA" (Mann-Whitney U-test). When Kruskal-Wallis ANOVAs were significant, these were followed by pairwise comparisons using Mann-Whitney $U$-tests.

${ }^{\text {a }}$ Range: 0-36; ns, non-significant $(p>.05)$; $* p<.05 ; * * p<.01 ; * * * p<.001$.

Values in parentheses are standard deviations. 
Table 2.

Consistency of the items of the Unusual Use of Objects Test.

\begin{tabular}{|c|c|c|c|c|c|c|c|c|}
\hline \multirow[b]{2}{*}{$\begin{array}{c}\text { Item } \\
\text { category }\end{array}$} & \multirow[b]{2}{*}{ Item } & \multicolumn{3}{|c|}{ Types of responses (\%) } & \multicolumn{4}{|c|}{ Effectiveness of responses $(\%)$} \\
\hline & & $\begin{array}{l}\text { Instrum. } \\
\text { part }\end{array}$ & Handle & Imposs. & $\begin{array}{c}\text { Correct } \\
\text { response }\end{array}$ & $\begin{array}{l}\text { Object } \\
\text { error }\end{array}$ & $\begin{array}{l}\text { Action } \\
\text { error }\end{array}$ & $\begin{array}{c}\text { Incorrect } \\
\text { impossible } \\
\text { response }\end{array}$ \\
\hline \multirow{9}{*}{$\begin{array}{l}\text { Instrum. } \\
\text { part }\end{array}$} & Bottle cap/screwdriver & 94 & 0 & 6 & 94 & 0 & 0 & 6 \\
\hline & Sheet of paper/knife & 100 & 0 & 0 & 90 & 0 & 10 & 0 \\
\hline & Milk brick/knife & 100 & 0 & 0 & 100 & 0 & 0 & 0 \\
\hline & Milk brick/pen & 90 & 1 & 9 & 90 & 1 & 0 & 9 \\
\hline & Milk brick/screwdriver & 94 & 0 & 6 & 90 & 0 & 4 & 6 \\
\hline & Nail/pliers & 98 & 2 & 0 & 98 & 2 & 0 & 0 \\
\hline & Screw/knife & 95 & 0 & 5 & 95 & 0 & 0 & 5 \\
\hline & Screw/scissors & 90 & 1 & 9 & 90 & 0 & 1 & 9 \\
\hline & Mean & 95 & 1 & 4 & 94 & 0 & 2 & 4 \\
\hline \multirow[t]{9}{*}{ Handle } & Yoghurt/brush & 13 & 79 & 8 & 79 & 13 & 0 & 8 \\
\hline & Yoghurt/fork & 24 & 76 & 0 & 76 & 24 & 0 & 0 \\
\hline & Nail/knife & 13 & 74 & 13 & 74 & 11 & 3 & 12 \\
\hline & Nail/corkscrew & 4 & 87 & 9 & 87 & 5 & 0 & 8 \\
\hline & Nail/screwdriver & 0 & 100 & 0 & 100 & 0 & 0 & 0 \\
\hline & Nail/saw & 17 & 79 & 4 & 79 & 17 & 0 & 4 \\
\hline & Nail/scissors & 2 & 83 & 15 & 83 & 2 & 0 & 15 \\
\hline & Sheet of paper/fork & 26 & 72 & 2 & 72 & 26 & 0 & 2 \\
\hline & Mean & 13 & 81 & 6 & 81 & 12 & 0 & 7 \\
\hline \multirow[t]{9}{*}{ Impossible } & Yoghurt/saw & 17 & 1 & 82 & 82 & 18 & 0 & - \\
\hline & Hazelnut/pen & 4 & 2 & 94 & 94 & 6 & 0 & - \\
\hline & Hazelnut/fork & 17 & 18 & 65 & 65 & 34 & 1 & - \\
\hline & Metal wire/corkscrew & 7 & 0 & 93 & 93 & 0 & 7 & - \\
\hline & Metal wire/hammer & 30 & 0 & 70 & 70 & 4 & 26 & - \\
\hline & Piece of wood/spoon & 7 & 0 & 93 & 93 & 7 & 0 & - \\
\hline & Piece of wood/scissors & 32 & 0 & 68 & 68 & 27 & 5 & - \\
\hline & Sheet of paper/razor & 9 & 2 & 89 & 89 & 9 & 2 & - \\
\hline & Mean & 15 & 3 & 82 & 82 & 13 & 5 & - \\
\hline
\end{tabular}

Values in bold correspond to instrumental-part, handle and impossible responses made in instrumental-part, handle and impossible items, respectively. 
Table 3.

Results of experimental tests.

\begin{tabular}{|c|c|c|c|c|c|c|c|c|}
\hline & Max. & $\begin{array}{c}\text { LBD } \\
(\mathrm{n}=20)\end{array}$ & $\begin{array}{c}\text { RBD } \\
(\mathrm{n}=11)\end{array}$ & $\begin{array}{l}\text { Control } \\
(\mathrm{n}=41)\end{array}$ & $\begin{array}{c}\text { All } \\
\text { groups }\end{array}$ & $\begin{array}{l}\text { LBD vs } \\
\text { RBD }\end{array}$ & $\begin{array}{l}\text { LBD vs } \\
\text { Control }\end{array}$ & $\begin{array}{l}\text { RBD vs } \\
\text { Control }\end{array}$ \\
\hline \multicolumn{9}{|l|}{ Conceptual knowledge } \\
\hline $\begin{array}{l}\text { Functional picture matching } \\
\text { (Associative) }\end{array}$ & 10 & $9.6(0.6)$ & $9.9(0.4)^{\mathrm{b}}$ & $9.9(0.2)$ & ns & - & - & - \\
\hline $\begin{array}{l}\text { Functional picture matching } \\
\text { (Categorical) }\end{array}$ & 10 & $8.8(1.2)$ & $8.6(1.5)^{b}$ & $9.9(0.3)$ & $* *$ & ns & $* *$ & ns \\
\hline Alternative object selection & 10 & $7.6(2.1)^{\mathrm{a}}$ & $8.6(1.3)$ & $9.8(0.5)$ & $* *$ & ns & $* *$ & $*$ \\
\hline Pantomime of object use & 14 & $11.9(2.0)$ & $12.6(1.4)$ & $13.1(0.8)$ & $*$ & $\mathrm{~ns}$ & $*$ & $\mathrm{~ns}$ \\
\hline Recog. of object utiliz. gestures & 20 & $17.3(2.6)$ & $18.2(1.9)^{\mathrm{b}}$ & $19.2(0.9)$ & $* *$ & $\mathrm{~ns}$ & $*$ & $*$ \\
\hline Conventional use of objects & 20 & $17.7(3.8)$ & $19.7(0.5)$ & $19.9(0.3)$ & $*$ & $\mathrm{~ns}$ & $*$ & $\mathrm{~ns}$ \\
\hline \multicolumn{9}{|l|}{ Unusual use of objects } \\
\hline \multicolumn{9}{|l|}{ Response type } \\
\hline Instrumental part & 48 & $23.8(7.6)$ & $17.0(3.4)$ & $19.4(3.0)$ & $*$ & $*$ & $*$ & $\mathrm{~ns}$ \\
\hline Handle & 48 & $9.4(7.0)$ & $14.5(2.9)$ & $13.4(2.0)$ & ns & - & - & - \\
\hline Impossible & 48 & $14.8(7.7)$ & $16.5(5.3)$ & $15.2(3.4)$ & $\mathrm{ns}$ & - & - & - \\
\hline \multicolumn{9}{|l|}{ Effectiveness of responses } \\
\hline Correct responses & 48 & $30.7(9.7)$ & $41.1(2.3)$ & $40.8(3.1)$ & $* *$ & $*$ & $* *$ & $\mathrm{~ns}$ \\
\hline Action errors & 48 & $7.1(4.7)$ & $3.4(3.0)$ & $1.2(1.4)$ & ns & - & - & - \\
\hline Object errors & 48 & $6.4(5.6)$ & $0.6(0.7)$ & $3.9(2.9)$ & $* *$ & $* *$ & $* *$ & $\mathrm{~ns}$ \\
\hline Inc. impossible responses & 48 & $3.8(4.9)$ & $2.9(2.8)$ & $2.1(1.8)$ & $\mathrm{ns}$ & - & - & - \\
\hline
\end{tabular}

Between-group comparisons were performed with Kruskal-Wallis ANOVAs. When Kruskal-Wallis ANOVAs were significant, these were followed by pairwise comparisons using Mann-Whitney $U$-tests.

${ }^{\mathrm{a}} \mathrm{n}=17 ;{ }^{\mathrm{b}} \mathrm{n}=7$; ns, non-significant $(p>.01) ; * p<.01 ; * * p<.001$.

Values in parentheses are standard deviations. 
Table 4.

Correlations between test results in LBD patients.

\begin{tabular}{|c|c|c|c|c|c|c|c|}
\hline & $\begin{array}{l}\text { Aphasia } \\
\text { severity }\end{array}$ & Assoc. & Categ. & Alter. & Panto. & Recog. & $\begin{array}{c}\text { Conventional } \\
\text { use }\end{array}$ \\
\hline Functional picture matching (Associative) & 0.37 & & & & & & \\
\hline Functional picture matching (Categorical) & $0.74 * *$ & 0.39 & & & & & \\
\hline Alternative object selection ${ }^{a}$ & 0.58 & 0.11 & 0.53 & & & & \\
\hline Pantomime of object use & 0.47 & 0.09 & 0.40 & 0.12 & & & \\
\hline Recognition of object utilization gestures & 0.29 & $0.68 *$ & 0.14 & 0.33 & 0.07 & & \\
\hline Conventional use of objects & $0.61 *$ & 0.55 & 0.34 & 0.08 & 0.16 & $0.57 *$ & \\
\hline Unusual use of objects (Correct responses) & $0.64 *$ & 0.32 & 0.39 & 0.26 & 0.10 & 0.47 & $0.76^{* *}$ \\
\hline
\end{tabular}

${ }^{\mathrm{a}} \mathrm{n}=17 ; * p<.01 ; * * p<.001$. 
Table 5 .

Individual performances of LBD and RBD patients in the Unusual Use of Objects Test.

\begin{tabular}{|c|c|c|c|c|c|c|c|c|c|c|c|}
\hline \multirow{3}{*}{ Group } & \multirow{3}{*}{ Subject } & \multirow{3}{*}{$\begin{array}{c}\text { Conven. } \\
\text { use of } \\
\text { objects }\end{array}$} & \multicolumn{9}{|c|}{ Unusual use of objects } \\
\hline & & & \multicolumn{5}{|c|}{ Types of responses (no.) } & \multicolumn{4}{|c|}{ Effectiveness of responses (no.) } \\
\hline & & & $\begin{array}{c}\text { Instrum. } \\
\text { part }\end{array}$ & Handle & Imposs. & $\begin{array}{c}\chi^{2} \\
(\mathrm{~d} f=2)\end{array}$ & $\begin{array}{l}\text { Signi. } \\
p<.01\end{array}$ & $\begin{array}{l}\text { Correct } \\
\text { resp. }\end{array}$ & $\begin{array}{l}\text { Action } \\
\text { errors }\end{array}$ & $\begin{array}{l}\text { Object } \\
\text { errors }\end{array}$ & $\begin{array}{l}\text { Inc. imp. } \\
\text { resp. }\end{array}$ \\
\hline \multirow[t]{20}{*}{ LBD } & L01 & 20 & 23 & 12 & 13 & 1.1 & & 32 & 7 & 8 & 1 \\
\hline & L02 & 16 & 22 & 10 & 16 & 1.2 & & 26 & 8 & 9 & 5 \\
\hline & L03 & 19 & 26 & 13 & 9 & 4.7 & & 33 & 5 & 10 & 0 \\
\hline & L04 & 20 & 26 & 12 & 10 & 4.1 & & 32 & 3 & 13 & 0 \\
\hline & L05 & 17 & 19 & $\mathbf{0}$ & 29 & 26.0 & $*$ & 22 & 6 & 6 & 14 \\
\hline & L06 & 11 & 37 & 6 & 5 & 26.8 & $*$ & 24 & 7 & 17 & 0 \\
\hline & L07 & 14 & 24 & 3 & 21 & 11.4 & $*$ & 25 & 11 & 4 & 8 \\
\hline & L08 & 20 & 26 & 0 & 22 & 18.7 & $*$ & 24 & 9 & 6 & 9 \\
\hline & L09 & 17 & 21 & 0 & 27 & 22.7 & $*$ & 17 & 15 & 3 & 13 \\
\hline & L10 & 14 & 42 & 0 & 6 & 45.1 & $*$ & 15 & 17 & 13 & 3 \\
\hline & L11 & 6 & 39 & 0 & 9 & 35.6 & $*$ & 12 & 20 & 14 & 2 \\
\hline & L12 & 20 & 22 & 14 & 12 & 1.0 & & 41 & 1 & 6 & 0 \\
\hline & L13 & 20 & 15 & 12 & 21 & 3.4 & & 42 & 1 & 0 & 5 \\
\hline & L14 & 20 & 20 & 17 & 11 & 2.1 & & 42 & 3 & 3 & 0 \\
\hline & L15 & 20 & 12 & 7 & 29 & 18.5 & $*$ & 35 & 0 & 0 & 13 \\
\hline & L16 & 20 & 21 & 23 & 4 & 15.2 & $*$ & 35 & 4 & 9 & 0 \\
\hline & L17 & 19 & 21 & 17 & 10 & 2.9 & & 36 & 3 & 9 & 0 \\
\hline & L18 & 20 & 21 & 15 & 12 & 1.0 & & 42 & 3 & 3 & 0 \\
\hline & L19 & 20 & 20 & 16 & 12 & 1.2 & & 42 & 2 & 4 & 0 \\
\hline & L20 & 20 & 18 & 13 & 17 & 0.3 & & 38 & 2 & 4 & 4 \\
\hline \multirow[t]{11}{*}{ RBD } & R01 & 20 & 22 & 21 & 5 & 11.5 & $*$ & 37 & 2 & 9 & 0 \\
\hline & R02 & 19 & 12 & 12 & 24 & 8.1 & & 40 & 0 & 0 & 8 \\
\hline & R03 & 19 & 18 & 14 & 16 & 0.2 & & 44 & 0 & 3 & 1 \\
\hline & R04 & 20 & 17 & 13 & 18 & 0.8 & & 42 & 1 & 2 & 3 \\
\hline & R05 & 20 & 14 & 12 & 22 & 4.7 & & 41 & 1 & 0 & 6 \\
\hline & R06 & 20 & 18 & 18 & 12 & 2.4 & & 43 & 1 & 4 & 0 \\
\hline & R07 & 19 & 18 & 15 & 15 & 0.3 & & 42 & 0 & 5 & 1 \\
\hline & R08 & 20 & 11 & 15 & 22 & 6.9 & & 42 & 0 & 0 & 6 \\
\hline & R09 & 20 & 19 & 15 & 14 & 0.3 & & 43 & 0 & 5 & 0 \\
\hline & R10 & 20 & 21 & 11 & 16 & 0.6 & & 37 & 1 & 7 & 3 \\
\hline & $\mathrm{R} 11$ & 20 & 18 & 13 & 17 & 0.3 & & 41 & 1 & 2 & 4 \\
\hline Control & Range & $19-20$ & $13-27$ & $8-18$ & $7-24$ & & & $34-47$ & $0-5$ & $0-11$ & $0-8$ \\
\hline
\end{tabular}

Values in bold are below the range of controls with the exception of response type, for which values below or above the range of controls are in bold only when the participant's response distribution is significantly different from mean control distribution by $\chi^{2}$ analysis. 


\section{FIGURE LEGENDS}

Fig. 1. Lesions of $16 \mathrm{LBD}$ patients onto templates from the atlas of Damasio and Damasio (1989). Case numbers refer to Table 5. Left and right are reversed.

Fig. 2. Lesions of 10 RBD patients onto templates from the atlas of Damasio and Damasio (1989). Case numbers refer to Table 5. Left and right are reversed.

Fig. 3. Item categories of the Unusual Use of Objects Test. The top panel shows an example of an instrumental-part item. The screw can be driven by inserting the blade of the knife into the slot. The corresponding instrumental-part response is represented. The middle panel illustrates an example of a handle item since the handle is more appropriate than the instrumental part of the fork to eat yoghurt. The drawing shows the corresponding handle response. The bottom panel represents an example of an impossible item. The corkscrew is not appropriate to cut the metal wire. An instrumental-part response is represented, but an impossible response is here expected.

Fig. 4. Multidimensional scaling of correlations between tests in LBD patients. 


\section{Figure 1}

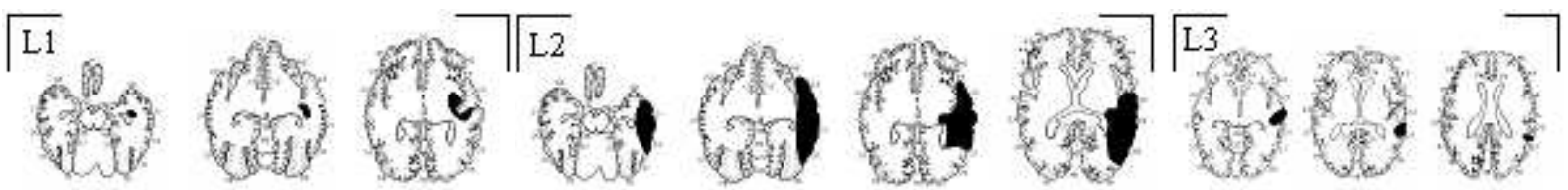

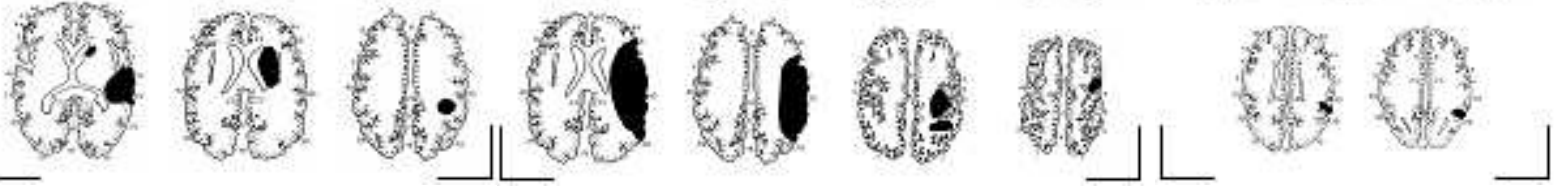

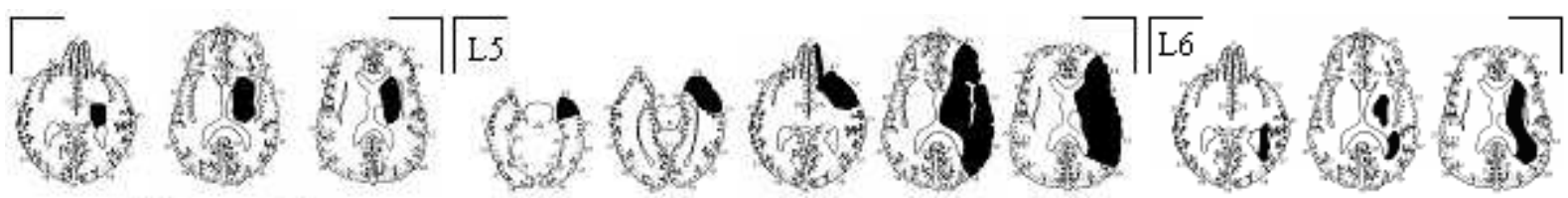

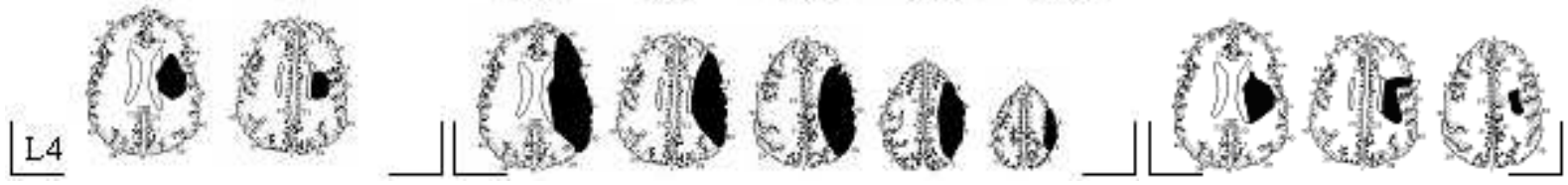
(4) (6)

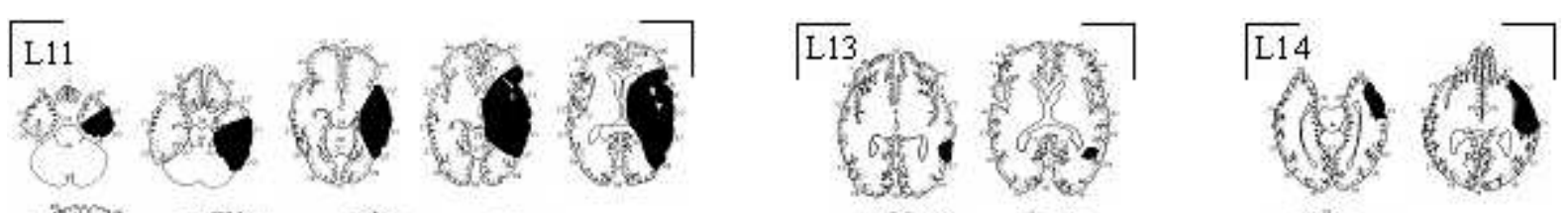

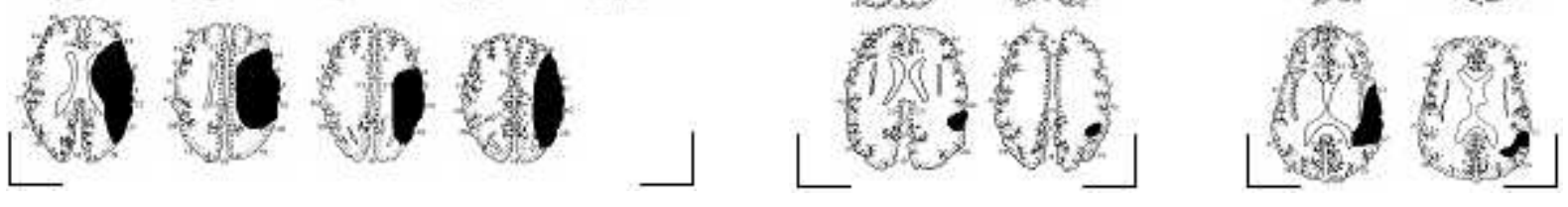

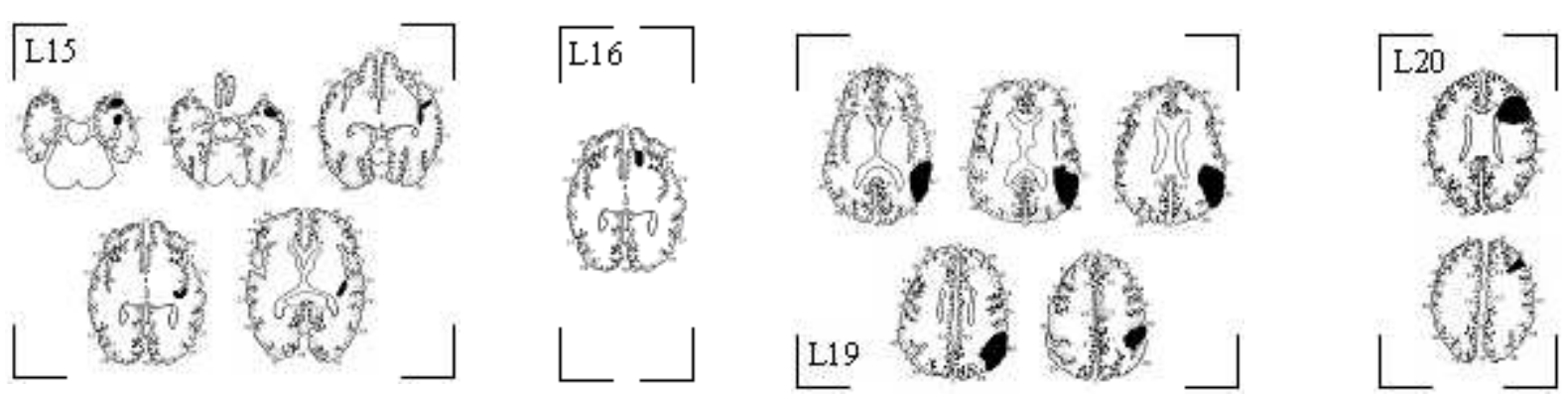




\section{Figure 2}

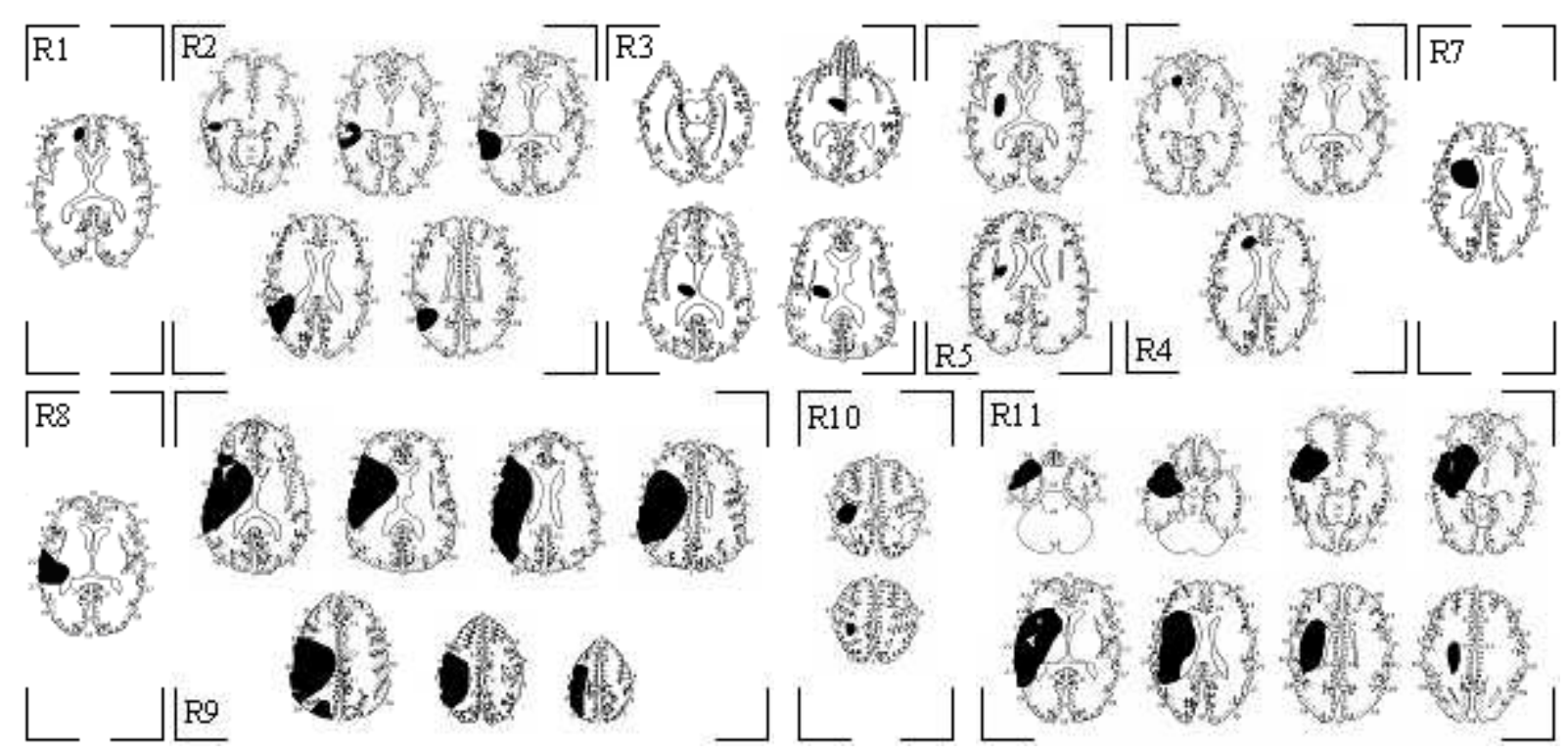




\section{Figure 3}

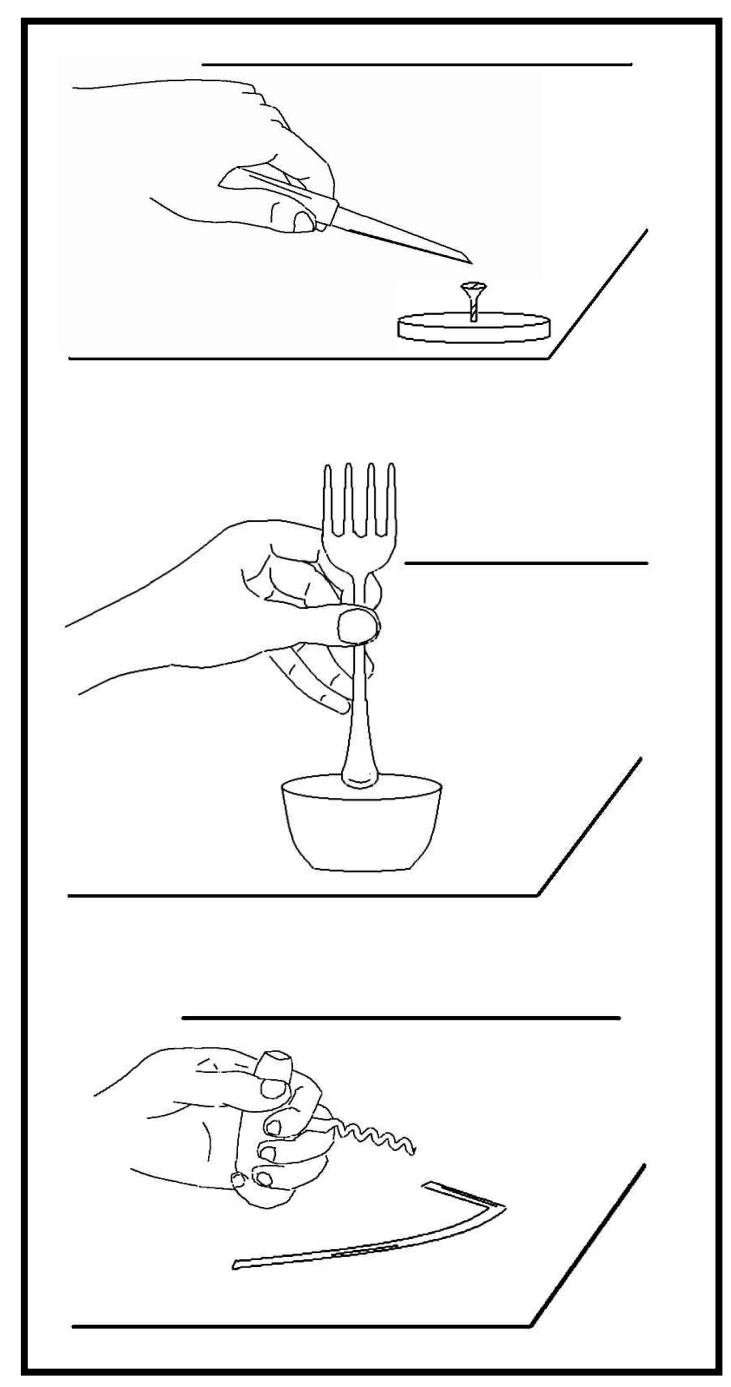




\section{Figure 4}

\begin{tabular}{|c|c|}
\hline Aph & $\begin{array}{c}\bullet \\
\text { sia severity }\end{array}$ \\
\hline $\begin{array}{l}\text { Conventional use } \\
\bullet \\
\text { Unusual use }\end{array}$ & $\begin{array}{r}\text { Alternative } \\
\text { Categorical } \\
\text { Pantomime } \\
\bullet\end{array}$ \\
\hline
\end{tabular}




\section{FoOTnOTE 1}

We follow the suggestion (Bozeat et al., 2002; Hartmann et al., 2005; Hodges et al., 2000) to use the terms "object" for the implement which performs an action (e.g., a hammer) and "recipient" for the recipient of the action (e.g., a nail).

\section{FOOTNOTE 2}

In line with Gibson's approach (Gibson, 1979), the technical reasoning model assumes that non-object-use actions, such as grasping or transporting objects, can be carried out on the basis of affordances, that is, the detection of complementarities of the individual and the environment. Affordances are relative to the physical feature of the individual and, as a result, serve to determine whether an object can be grasped or not, which handgrip is the most comfortable, etc. (see Goodale et al., 1994; Rosenbaum et al., 1990). Importantly, Gagnepain (1990) emphasized that object use is not guided by the ability to detect complementarities between the user and the environment, but solely by the ability to reason about technical relationships that can be detected within the environment. For instance, individuals do not choose to grasp the free extremity of the handle of a hammer because it provides the most comfortable grip, but because it provides the best way to amplify the strength of percussion (i.e., lever-type action). However, an individual with impaired technical reasoning might not determine that the free extremity of the handle must be grasped to perform the action in the best way, but would nevertheless choose to grasp the handle of the hammer because it provides a more comfortable grip than the head.

\section{Footnote 3}

Spearman rank order correlations were used to study relationships between education level and all the experimental variables. Since these analyses, conducted separately for LBD and RBD patients, did not yield any significant effects, this variable was not further considered in the statistical analyses. 


\section{FoOTNOTE 4}

Each control subject's response distribution was also compared to the mean control distribution. Statistics using $\chi^{2}$ analyses revealed that $\chi^{2}$ values observed in controls were nonsignificant at the .01 level. Maximum $\chi^{2}$ value was 6.64 .

\section{FOOTNOTE 5}

It is noteworthy that association between pantomime of object use and actual use of objects has been reported when patients are requested to execute pantomime to sight of objects (Goldenberg and Hagmann, 1998; Osiurak et al., 2008a). In contrast, by asking patients to imitate pantomimes, we did not find such association. These divergent results raise the question of whether, beyond the traditional account for selective modality deficits (e.g., visual/gestural input versus visual/object input; Rothi et al., 1991), the same cognitive processes are really involved when pantomimes of object use have to be imitated or produced to sight of objects. 